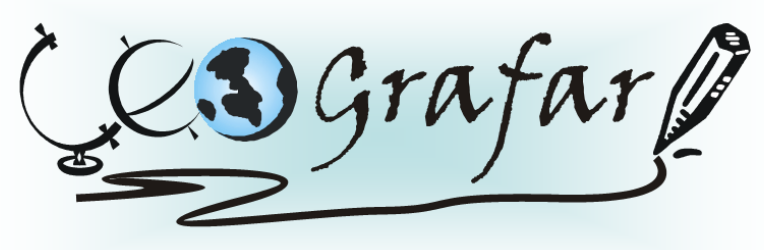

Revista Eletrônica do Programa de Pós-Graduação em Geografia - UFPR

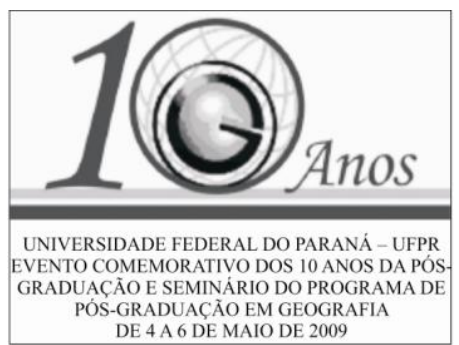

\title{
HIDRELÉTRICAS DO RIO MADEIRA: TECNIFICAÇÃO, IMPACTOS E (RE)ORGANIZAÇÃO DO TERRITÓRIO
}

\author{
MARIA MADALENA DE A. CAVALCANTE ${ }^{1}$ \\ LEONARDO JOSÉ CORDEIRO SANTOS ${ }^{2}$
}

\section{LINHA DE PESQUISA: PAISAGEM E ANÁLISE AMBIENTAL}

\begin{abstract}
Resumo: O objetivo do trabalho de pesquisa é analisar o processo de (re)organização territorial na área de influência das hidrelétricas no Rio Madeira - distritos de Abunã, Mutum-Paraná e Jaci-Paraná - Município de Porto Velho, Estado de Rondônia/Brasil, relacionando as contradições sociais e ambientais envolto na construção das usinas, bem como os impactos espaço-temporal. A discussão teórica e metodológica baseia-se na relação sociedade e espaço no processo de apropriação do território. A metodologia adotada permite definir o elenco dos atores existentes na área, suas intencionalidades e possíveis contradições inerentes ao uso do território. A conclusão das obras está prevista para o ano de 2013 e entre outras mudanças destaca-se à restrição das atividades de pesca, garimpo e cultivo de várzea; enquanto que a atuação dos madeireiros, fazendeiros e colonos se expandem, contribuindo para a retirada da cobertura vegetal e pressão em unidades de conservação e terras indígenas, tornando incoerentes as políticas de desenvolvimento e de sustentabilidade ambiental.
\end{abstract}

Palavras chaves: Hidrelétricas; Território; Impactos.

\section{INTRODUÇÃO}

A tecnificação do território é uma das condições básicas da globalização e faz com que determinadas áreas na Amazônia sejam (re)funcionalizadas para suprimento de demandas externas à região. A problemática consiste em compreender que mudanças estruturais passam a compor o território com a construção das hidrelétricas no Rio Madeira e quais contradições são inerentes a esta mudança. A hipótese é de que as hidrelétricas constituem uma nova materialidade, mas não exclui antigos modelos de exploração e apropriação dos recursos naturais o que mudas são as escalas de apropriação e a velocidade com que isto ocorre, tencionando os conflitos entre os agentes atuantes.

\section{METODOLOGIA}

\footnotetext{
1 mada.geoplan@gmail.com

${ }^{2}$ Professor orientador
} 
A metodologia proposta está fundamentada no conceito de espaço elaborado por Milton Santos (1992 e 1991), como um conjunto indissociável e também contraditório de sistemas de ações e sistemas de objetos, elegendo os elementos que o constitui: a sociedade dividida em agentes sociais, econômicos e institucionais; As técnicas apresentam-se como elementos intermediários entre a sociedade e espaço, sendo os meios utilizados pelos agentes, para a apropriação do espaço; E por fim o espaço ou meio ecológico que consiste na natureza transformada (SANTOS, 1992). Tais elementos se interagem num processo dinâmico, mas aqui sua divisão se faz necessária conforme FIGURA 1, para então detectar quais os agentes mais proeminentes, como utilizam determinadas técnicas para a apropriação do espaço e com qual intencionalidade.

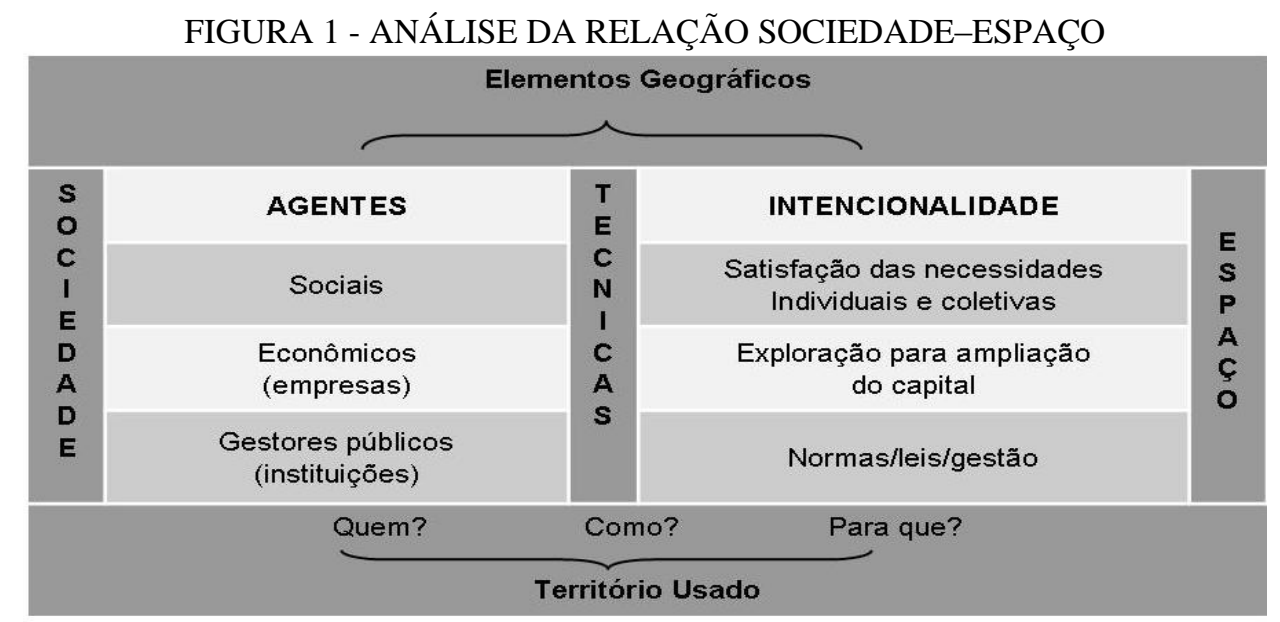

Adaptado a partir de Santos, 1996 e 1992.

A estrutura metodológica subdivide os agentes em grupos, descritos por:

a) Atores sociais constituídos pela sociedade civil organizada. Neste, as associações de garimpeiros, pescadores e agricultores familiares, cuja intencionalidade é a satisfação de suas necessidades, sejam elas individuais ou coletivas.

b) Agentes econômicos, sendo os madeireiros, pecuaristas, agricultores e empresas (construtora das barragens) apropriam-se do espaço para a ampliação do capital, e que neste último, se diferenciam entre os demais pelas escalas de atuação e apropriação dos recursos naturais.

c) Gestores públicos, que são representados pelas instituições e administradores locais. Estes buscam normatizar o uso do território e os recursos naturais através de leis, 
como, no caso de Rondônia, o próprio Zoneamento Socioeconômico e Ecológico Estadual ZSEE, Lei Complementar No 233 de 06 de julho de 2000.

Uma vez identificados os grupos atuantes, a metodologia possui a seguinte etapa operacional:

1) Preparação das bases cartográficas: disposição em mapas dos elementos geográficos e identificação da área de influência do reservatório;

2) Coleta de dados: incide sobre um conjunto de procedimentos e técnicas, para obtenção de dados quantitativos e qualitativos, seja de modo secundário ou primário - para os dados secundários utiliza-se pesquisa bibliográfica e relatórios setoriais em órgãos públicos (Federal, Estadual e Municipal), referentes a séries estatísticas, dados socioeconômicos e os de instrumentos de gestão existentes na área. Já os dados primários são adquiridos a partir de observações de campo, entrevistas, anotações em formulários, entre outros previstos pra 2010.

3) Integração dos dados: os dados incorporados na análise têm como ponto de partida o banco de dados produzido em 2005 pelo Laboratório de Geografia e Planejamento Ambiental da Universidade Federal de Rondônia LABOGEOPA/UNIR, sobre a área de influência do reservatório, comparando aos dados que serão atualizados em 2010, possibilitando assim a avaliação espaço-temporal das variáveis: migração, atividades econômicas, uso e tendências à ocupação do solo, entre outras.

4) Avaliação e determinação dos impactos: constitui o cruzamento das informações já mencionadas, como o Zoneamento Estadual e legislações afins, aliado a instrumentos cartográficos e imagens de satélite para analogias, ordenação e representação de tendências dos impactos e conflitos na (re)organização do território.

\section{Algumas Reflexões}

O conjunto de políticas públicas territoriais exercidas na Amazônia é caracterizado pela implantação de grandes obras de infra-estrutura como parte dos planos estratégicos nacionais, apresentados à sociedade, sendo essenciais ao desenvolvimento. Na região do Alto rio Madeira, este processo é marcado pela apropriação dos recursos naturais, ocasionando uma desestruturação na organização social, cujo quadro de instabilidade social, ambiental e econômica tende a ser elevados (KOHLHEPP, 2002; CAVALCANTE, 2007). 
Para efeito de planejamento, os impactos podem ser classificados em: a) impactos especulativos - os quais são anteriores à implantação das hidrelétricas como crescimento populacional, dados à expectativa de geração de emprego e especulações mobiliaria; $b$ ) impactos imediatos ocasionados a partir da materialização das hidrelétricas, ou seja, como pré-requisito para que eles ocorram, a exemplo do deslocamento populacional da área de influência do reservatório, neste caso a remoção de todo núcleo urbano de Mutum-Paraná, perda de áreas produtivas, vegetação, entre outros; c) e por fim, impactos processuais que são os desencadeados pela obra e somados aos conflitos já existentes. Tal entendimento, ao ser considerado no planejamento pelos gestores públicos contribui para que os desequilíbrios sejam contidos, a partir e posterior à obra.

\section{CONSIDERAÇÕES}

A tecnificação da região do Alto Rio Madeira é motivada pelo uso dos recursos naturais e têm na construção das hidrelétricas a (re)funcionalização da região para a atuação estatal e privada, no atendimento de demandas externas, desvinculando esta obra da realidade local, desestruturando sua dinâmica gerando um quadro de instabilidade social, econômica e ambiental

\section{REFERÊNCIAS}

CAVALCANTE M. M. A., et. all. Territorial transformations In the Amazon: Natural resources usage at Region Alto Madeira Rondônia, Brazil. In: International Congresso n Devolopment and natural resources: Mult-level and mult-scale Sustainability, Cochabamba, 2007.

KOHLHEPP, G. Conflitos de interesse no ordenamento territorial da Amazônia brasileira. Estudos Avançados, vol.16, ISSN 0103-4014, 2002. Disponível em http://www.scielo.br/pdf/ea/v16n45/v16n45a04.pdf. Acesso 23/01/2009.

SANTOS, M. A natureza do Espaço: Técnica e Tempo, Razão e Emoção. São Paulo: Hucitec, 1996.

SANTOS, M. Espaço e método. $3^{\text {a }}$ ed. São Paulo: Nobel, 1992.

SANTOS, M. Metamorfose do espaço habitado: Fundamentos Teórico e Metodológico da Geografia. São Paulo: Hucitec, 1991. 